\title{
EM BUSCA DE JUSTIÇA AO JOVEM: A DIFÍCIL ARTICULAÇÃO ENTRE OS PODERES
}

\author{
Karyna Batista Sposato e Marisa Meneses de Andrade
}

IN SEARCH OF JUSTICE FOR THE YOUNG: THE PROBLEMATIC ARTICULATION BETWEEN PUBLIC POWERS

\section{RESUMO}

ESTE ARTIGO SE PROPÕE A ANALISAR O ALCANCE DA INICIATIVA levada a cabo pelo Conselho nacional de Justiça (CNJ) ATRAVÉS dO PROgRama Justiça AO JOVEM A PARTIR DE DOIS ASPECTOS CENTRAIS: A) A FORMULAÇÃO DE SUBSÍDIOS PARA A IMPLEMENTACÄO DA LEI N. 12.594/2012 - SINASE POR PARTE DOS PODERES EXECUTIVOS ESTADUAIS, E B) A ELABORAÇÃO DE AUTORRECOMENDACÕES AO PODER JUDICIÁRIO NO ATENDIMENTO DA EXIGÊNCIA DE ESPECIALIZAÇÃO E ABRANGÊNCIA TERRITORIAL DA JUSTIÇA DA INFÂNCIA E JUVENTUDE COMO FORMA DE GARANTIR OS DIREITOS DE ADOLESCENTES EM CONFLITO COM A LEI. PARA TANTO, ALÉM DE UMA REVISÃO SOBRE O PROCESSO DE REFORMA DO JUDICIÁRIO BRASILEIRO E A IMPLEMENTAÇÃO DO PRÓPRIO CONSELHO, NOS DEBRUCAMOS SOBRE A SITUACÃO DO ADOLESCENTE EM PRIVAC̣ÃO DE LIBERDADE EM SEU COTEJO COM A CONTRIBUICÃO DADA PELO CNJ. NESSE PERCURSO, EVIDENCIASE QUE A BUSCA POR MAIS JUSTIÇA AOS JOVENS ESBARRA PARADOXALMENTE EM DECISÕES E ATOS EMANADOS DO PRÓPRIO PODER JUDICIÁRIO, ABRINDO-SE UM ESPECTRO DE REFLEXÃO EM TORNO DA DIFÍCIL ARTICULACCÃO ENTRE O QUE RECOMENDA O CNJ E AS CRISTALIZADAS PRÁTICAS INSTITUCIONAIS.

\section{PALAVRAS-CHAVE}

AdOLESCENTES EM CONFLITO COM A LEI; ATENDIMENTO Socioeducativo; CNJ; SINASE; Programa Justiça ao Jovem.

\section{ABSTRACT}

THIS ARTICLE ANALYZES THE INITIATIVE OF THE NATIONAL JUSTICE COUNCIL REGARDING ITS JUSTICE FOR THE YOUNG PROGRAM THROUGH TWO MAIN ASPECTS: A) THE ISSUES STATEMENTS FOR THE IMPLEMENTATION OF THE LAW

N. 12.594/2012 - KNOWN AS SINASE AND BI THE ELABORATION OF SELF RECOMMENDATIONS TO THE JUDICIARY IN ORDER TO FULFILL THE NECESSITIES OF SPECIALIZATION AND TERRITORIAL COVERAGE AS A WAY TO GUARANTEE JUVENILE RIGHTS. THEREFORE, BESIDES A REVISION ABOUT THE REFORMS OF THE BRAZILIAN JUDICIAL SYSTEM, AND THE IMPLEMENTATION OF THE COUNCIL ITSELF, WE FOCUS ON THE SITUATION OF ADOLESCENTS IN PRIVATION OF FREEDOM AND THE CONTRIBUTION GIVEN THROUGH THE NATIONAL Justice COUNCIL. Also, there ARE EVIDENCES THAT THE SEARCH OF A FAIRER JUSTICE FOR THE YOUNG COLLIDES WITH THE ACTS AND DECISIONS OF THE JUDICIAL POWER, WHICH OPENS AN SPECTRUM OF REFLECTIONS ABOUT THE PROBLEMATIC ARTICULATION BETWEEN THE NATIONAL JUSTICE COUNCIL'S RECOMMENDATION'S AND THE ORDINARY INSTITUTIONAL'S PRACTICES.

\section{KEYWORDS}

ADOLESCENTS IN CONFLICT WITH THE LAW; SOCIOEDUCATIVE SYSTEM; CNJ; SINASE; YOUNG JUSTICE PROGRAM.

\section{INTRODUÇÃO}

Desde a Constituição Federal de 1988 observa-se no Brasil um intenso processo de reformulação e transmutação da órbita do Poder Judiciário e de sua atuação. Questões de ordem política que influenciam sobremaneira o cotidiano da sociedade brasileira 
contemporânea acabam por desaguar no Supremo Tribunal Federal em especial. Mas não é só isso. A chamada judicialização da política, entendida como "a utilização de procedimentos judiciais para a resolução de conflitos de ordem política, tais como controvérsias a respeito de normas, resoluções e políticas em geral, adotadas/implementadas pelos poderes Executivo e Legislativo" (OLIVEIRA, 2005, p. 559), faz realçar esse novo papel institucional do Judiciário.

Quando as leis deixam de trazer uma definição concreta do objetivo do legislador, para então estabelecerem conceitos indeterminados, princípios a serem observados, transfere-se o conflito para as mãos do Judiciário, que passa também a definir qual o objetivo das normas (WATANABE, 2004. p. 44 e 45).

De outra parte, a prestação jurisdicional cada vez mais tem se constituído como serviço público, e a Justiça de maneira geral passa a ser vista também como política pública, iniciando-se então um vultoso debate acerca do conteúdo proferido em decisões judiciais e também acerca do modelo organizacional desse Poder e a maneira com que ele se relaciona com a sociedade (BOTTINI, 2009, p. 14).

Celso Campilongo esclarece que a expansão do Judiciário é fenômeno global, em grande medida associado à explosão de expectativas depositadas na Justiça. Lança o autor sete desafios de base para a administração de uma Justiça respeitada, dentre os quais nos interessa particularmente aquele que insta a burocracia judicial a perceber que, por conta de desequilíbrios sociais históricos, sua missão é menos de estabilização da ordem e mais de desestabilização da desordem; menos de garantia de direitos e mais de afirmação de direitos nunca garantidos; menos de inclusão e mais de eliminação de privilégios daqueles excessivamente incluídos; menos de politização ou de mercantilização do direito e mais, simplesmente, de aplicação do próprio direito (CAMPILONGO, 2011, p. 81).

Nessa passagem de um modelo de administração formalista e procedimentalista para outro de dimensões participativas e conteudísticas, desponta na experiência brasileira, no ano de 2004, a Emenda Constitucional n. 45, cujo objetivo esteve e está direcionado a aumentar a capilaridade do sistema judicial brasileiro, tornando-o mais acessível e ágil, viabilizando a solução institucional de certos conflitos que, em razão do excesso de tempo e da distância da justiça, terminavam por ser resolvidos na arena privada (RIBEIRO, 2008, p. 469).

Da criação do Conselho Nacional de Justiça (CNJ) pela EC n. 45 e sua organização estrutural deve-se sublinhar a participação de representantes de Tribunais das mais variadas instâncias, mas também de representantes da Ordem dos Advogados do Brasil, do Ministério Público e da sociedade civil - permitindo inferir que esse órgão tem por escopo funcionar como via de comunicação entre o Poder Judiciário e setores dos movimentos sociais e organizações da sociedade civil. Logo, o CNJ pode justamente simbolizar "a porta de entrada do Judiciário para as ideias, críticas e sugestões relacionadas ao funcionamento da justiça, sob a ótica de serviço público” (LAVIGNE, 2010, p. 
73).

Tal perspectiva encontra ressonância na ideia de governança judicial - termo utilizado ao se tratar de medidas relacionadas à administração do Judiciário (AKUTSU; GUIMARÃES, 2012, p. 184). Conforme Akutsu e Aquino Guimarães, a governança judicial depende não somente das dimensões independência e accountability, mas também de dimensões relacionadas às características e circunstâncias dos órgãos do Poder Judiciário; no dizer desses autores, "recursos estratégicos do Poder Judiciário”, “acessibilidade à Justiça” e “estrutura do Poder Judiciário” (AKUTSU; GUIMARÃES, 2012, p. 192).

Esses temas estão profundamente conectados ao conceito de accountability no campo da Justiça. Em sentido genérico, Ilton Filho os conceitua como "necessidade de uma pessoa ou instituição que recebeu uma atribuição ou delegação de poder prestar informações e justificações sobre suas ações e seus resultados, podendo ser sancionada política, pública, institucional e/ou juridicamente por suas atividades" (FILHO, 2013, p. 30).

São dois os tipos clássicos de accountability: vertical (eleitoral e social) e horizontal. $\mathrm{Na}$ accountability vertical eleitoral, através de eleições os cidadãos podem sancionar os agentes estatais em razão da avaliação de seus atos e pelos resultados obtidos por representantes e autoridades eleitas. Já na accountability vertical social, a sanção é feita através das organizações da sociedade e da imprensa, seja por meio de denúncias ou de exposição pública. Agrega-se à tal diferença a possibilidade de tal sanção se destinar a agentes estatais eleitos ou não. Por último, a accountability horizontal, também denominada institucional, se dá quando agentes estatais podem requerer informações e justificações de outros agentes estatais, podendo inclusive sancioná-los (FILHO, 2013, p. 30).

Na história recente brasileira, a governança judicial se concretiza através da criação e funcionamento do Conselho Nacional de Justiça, ao qual compete planejar e estabelecer diretrizes gerais para o desenvolvimento de serviços de prestação jurisdicional: é papel do Conselho ordenar soluções e caminhos a respeito dos atos rotineiros de administração do Judiciário (BOTTINI, 2009, p. 71).

Nesse sentido, há um aspecto singular na atuação do CNJ no tocante ao monitoramento e fiscalização do sistema de controle penal brasileiro, não só resultando na construção de um novo olhar para a política penitenciária do país mas também almejando o aprimoramento do sistema de atendimento socioeducativo destinado aos adolescentes em conflito com a lei.

Com foco nesse contexto particular, analisamos o alcance do Programa Justiça ao Jovem realizado pelo Conselho Nacional de Justiça, procurando discutir sua capacidade de irradiação positiva no cenário de recente implementação da Lei n. 12.594/2012 conhecida como Lei do SINASE. Também discutiremos a paradoxal contradição entre as recomendações tecidas ao Poder Judiciário no atendimento da exigência de espe- 
cialização e abrangência territorial da justiça da infância e juventude como forma de garantir os direitos de adolescentes em conflito com a lei e as decisões e atos emanados do próprio Poder Judiciário em franca oposição aos ditames legais relacionados ao sistema de atendimento socioeducativo.

Se por um lado é inegável que os resultados do Programa Justiça ao Jovem repercutem na política de atendimento a adolescentes em conflito com a lei, impactando os poderes executivos em seus três níveis de governo (federal, estadual e municipal), a mesma ressonância parece não se verificar no âmbito da própria Justiça.

A tematização desses aspectos se desenvolve neste artigo em cinco seções. A seção 1 aborda o Programa Justiça ao Jovem, desenvolvido pelo CNJ em face da execução da medida socioeducativa de internação no país. A seção 2 discute o papel do Judiciário no monitoramento e fiscalização das medidas socioeducativas, sem que isso represente qualquer interferência nas prerrogativas de competência do Poder Executivo. A seção 3 aborda a necessidade de especialização da justiça da infância e juventude para o adequado trato de questões referentes ao adolescente, e a seção 4 analisa criticamente uma recente decisão emanada do Supremo Tribunal Federal em franca contradição às diretrizes legais e recomendações do próprio Conselho Nacional de Justiça. Por derradeiro, apresentam-se algumas considerações finais.

\section{i O Programa Justiça Ao Jovem}

A Lei n. 12.106/2009, no âmbito do Conselho Nacional de Justiça, criou o Departamento de Monitoramento e Fiscalização do Sistema Carcerário e do Sistema de Execução de Medidas Socioeducativas (DMF/CNJ). Segundo Ilton Filho, mediante a atuação desse Departamento, o Conselho "realiza accountability horizontal sobre os agentes estatais que atuam nos referidos sistemas" (FILHO, 2013, p. 43). Dentre os objetivos desse Departamento, especificados no artigo $1^{\circ}$ da Lei, estão: monitorar e fiscalizar o cumprimento das recomendações e resoluções do Conselho em relação à medida de segurança e de internação de adolescentes (inciso I) e acompanhar e monitorar projetos relativos à abertura de novas vagas e ao cumprimento da legislação pertinente em relação ao sistema de execução de medidas socioeducativas (inciso VI).

A atuação do Conselho para o aperfeiçoamento do sistema de atendimento socioeducativo se concentra no desenvolvimento do Programa Justiça ao Jovem, que vem a público mediante divulgação no ano de 2010 pelo DMF/CNJ. O Programa visou realizar uma radiografia nacional a respeito da maneira como se dá a execução da medida socioeducativa de internação, garantindo aos socioeducandos os direitos previstos pelo Estatuto da Criança e do Adolescente (ECA) e pela Lei n. 12.594/2012, que institui o Sistema Nacional de Atendimento Socioeducativo (SINASE). ${ }^{1}$

Por meio do Programa Justiça ao Jovem realizou-se um estudo de campo em todos os estados da Federação, incluindo o Distrito Federal, visando abordar as condições 
estruturais físicas das unidades de internação, o atendimento prestado ao adolescente em cumprimento de medida de internação e a forma de tramitação dos processos de execução de medida socioeducativa. Tal estudo teve como resultado o relatório Panorama Nacional - A Execução das Medidas Socioeducativas de Internação. Nesse documento destaca-se que a principal finalidade do trabalho então desenvolvido é aportar subsídios à atuação do Conselho Nacional de Justiça na adoção de políticas orientadoras para o Sistema de Garantia de direitos dos jovens que cumprem medida socioeducativa de internação (CNJ, 2012 i, p. 7).

A investigação social sobre a situação em que vivem os adolescentes internados sob cuidado do Estado levada a cabo pelo Programa Justiça ao Jovem representa um trabalho sem precedentes no âmbito da pesquisa empírica sobre o sistema de Justiça Infantojuvenil, não só devido a sua abrangência geográfica e institucional como também - e sobretudo - em face de seu protagonista: o observador é propriamente um órgão jurisdicional voltado a garantir uma melhor atuação e funcionamento do próprio sistema de justiça. É dizer que, através da realização de diagnóstico sobre a execução das medidas socioeducativas, como enfatiza o próprio Conselho, pode-se construir políticas bem orientadas para o aperfeiçoamento do sistema de Justiça (CNJ, 2012 i, p. 9). Em outras palavras, conhecer em profundidade a execução da medida socioeducativa possibilita identificar caminhos para o aperfeiçoamento da própria justiça.

\section{JustiçA E POLÍTica SOCIOEDUCATIVA}

O artigo 88, inciso V, do Estatuto da Criança e do Adolescente (Lei n. 8.069/90), define como diretriz para a política de atendimento a integração operacional de órgãos do Judiciário, Ministério Público, Defensoria, Segurança Pública e Assistência Social, preferencialmente em um mesmo local, para efeito de agilização do atendimento inicial a adolescente a quem se atribua autoria de ato infracional.

Assoma-se a compreensão de que o Sistema de Garantia de Direitos inclui princípios e normas que regem a política de atenção aos adolescentes, cujas ações são promovidas pelo Poder Público, em suas três esferas (União, Estados, Distrito Federal e Municípios), pelos Poderes Executivo, Legislativo e Judiciário e, também, pela sociedade civil, sob três eixos: promoção, defesa e controle social. A opção pela forma de sistema objetiva melhor ordenar os inúmeros quesitos que permeiam a temática, reduzindo-se, dessa maneira, a complexidade intrínseca do atendimento aos direitos desse público (CEDCA/PE, 2010).

É de se observar que a crescente participação do Poder Judiciário na definição e determinação de políticas públicas tem resultado em uma nova configuração para a repartição de poderes. Resta pacífico o entendimento de que a execução das medidas socioeducativas é matéria de competência exclusiva do Poder Executivo - em seus 
dois níveis de governo, ou seja, estadual, para as medidas privativas da liberdade, e municipal, para as executadas em meio aberto. Em contrapartida, é certo que cabe ao juiz - compreendendo a prestação jurisdicional como serviço público - promover ações que concretizem os direitos e garantias do adolescente, principalmente quando custodiado pelo Estado.

Maria Tereza Sadek aponta duas faces do Poder Judiciário. Uma diz respeito à função jurisdicional de prestação de serviços, cuja atuação é pautada em arbitrar conflitos e garantir direitos. A outra face é a política, de poder de Estado, propiciada pela Constituição de 1988 ao conceder ao Judiciário capacidade para agir politicamente, "quer questionando, quer paralisando políticas e atos administrativos, aprovados pelos poderes Executivo e Legislativo, ou mesmo determinando medidas, independentemente da vontade expressa do Executivo e da maioria parlamentar" (SADEK, 2004). A pesquisadora explica que a Carta Política de 1988, resultante de um processo de redemocratização, não tem pretensão exclusiva de limitar o poder absoluto e assegurar direitos; quer também ser instrumento de realização da justiça social e da promoção de direitos. Consequentemente, "o foco central passa a estar em questões concretas, de natureza social, política e econômica”, o que faz embaçar as divisas entre o direito e a política (SADEK, 2004).

No mesmo sentido estão as considerações lançadas por Campilongo, quando elabora a distinção entre o Direito como regras do jogo, no Estado liberal, e o Direito como instrumento que viabiliza as metas, no Estado de Bem-Estar social (CAMPILONGO, 2011, p. 148). O autor aprofunda ainda mais sua reflexão na esteira do que defende Sabino Cassese, segundo o qual "a normatividade jurídica caminha para uma terceira etapa: nem regra do jogo, nem objetivo das regras, mas um ‘jogo com as regras'. Ora, o direito, apesar de não se confundir com a política, sempre terá repercussão sobre a política”. (CAMPILONGO, 2011, p. 148).

Não é outro o entendimento que deriva da combinação entre a Lei do SINASE, enquanto marco regulatório de todo o sistema de atendimento socioeducativo (e por consequência, de toda a política socioeducativa) e a Resolução n. 165/2012 do CNJ, que normatiza a ampliação da presença e atuação do Poder Judiciário. ${ }^{2}$

Nessa perspectiva, o Programa Justiça ao Jovem representa um ponto de partida de substancial significado para a operacionalização do sistema de atendimento no âmbito dos poderes executivos sob novas bases e para a conscientização do próprio Poder Judiciário no que diz respeito ao problemático panorama encontrado na execução de medidas socioeducativas de internação.

\section{EsPeCializaçÃO da JUSTIÇA COMO CONDIÇÃO DE JUSTIÇA}

Conforme apontam as Nações Unidas, em alguns países os jovens em conflito com a lei são tratados pelo sistema de justiça criminal pertinente aos adultos. Não existe, nes- 
ses casos, uma justiça especial, e, sendo assim, tais adolescentes não são tratados de acordo com sua condição peculiar de desenvolvimento, e podem passar por polícias, juízes, tribunais e prisões comuns. Já em outros Estados existem legislações e instituições particularizadas para as crianças e adolescentes, conformando um sistema de justiça juvenil. Nos países onde tal sistema especializado existe, à exceção dos lugares em que ele funciona como parte do sistema de justiça criminal adulto, há uma preocupação crescente em se construir instituições ou elaborar procedimentos específicos para jovens, tais como tribunais juvenis ou polícias juvenis (ONU, 2009).

Em verdade, a especialização da justiça da infância e juventude guarda profunda relação com a recomendação derivada da Convenção Internacional das Nações Unidas sobre os Direitos da Criança e outros instrumentos internacionais no âmbito das Nações Unidas, no tocante ao estabelecimento de uma idade mínima para o início da responsabilidade de menores de 18 anos que praticam infrações penais. Tal estabelecimento reflete o reconhecimento da dignidade humana de todo adolescente, o que impõe a existência de uma justiça especializada que introduza em seu funcionamento o critério de sanção mais adequado para cada caso concreto, com atenção à condição peculiar de desenvolvimento em que o adolescente se encontra (SPOSATO, 2013, p. 226).

Por tais razões, o ECA dita a especialização da justiça nos temas da infância e juventude. Em seu artigo 145, por exemplo, há a previsão de que os estados e o Distrito Federal criem varas especializadas e exclusivas da infância e da juventude, dando responsabilidade ao Poder Judiciário de estabelecer sua proporcionalidade por número de habitantes, dotá-las de infraestrutura e dispor sobre o atendimento.

Com o intuito de reforçar a orientação para a instalação de Varas da Infância e Juventude e oferecer um direcionamento mais incisivo para o sistema de justiça, o Conselho Nacional dos Direitos da Criança e do Adolescente (Conanda) aprovou a Resolução n. 113/2006. Tal Resolução, em seu art. 9º, inciso I, estabelece que o Poder Judiciário, o Ministério Público, as Defensorias Públicas e a Segurança Pública deverão ser instados no sentido da exclusividade, especialização e regionalização dos seus órgãos e de suas ações, garantindo a criação, implementação e fortalecimento de Varas da Infância e da Juventude específicas, em todas as comarcas que correspondam a municípios de grande e médio porte ou outra proporcionalidade por número de habitantes, dotando-as de infraestruturas e prevendo regime de plantão para elas.

Outro estudo realizado em 2012 pelo Conselho Nacional de Justiça - através do Departamento de Pesquisas Judiciárias (DPJ) -, pelo Instituto de Pesquisa Econômica Aplicada (Ipea) - através da Diretoria de Políticas e Estudos Sociais (Disoc) - e pela Diretoria de Políticas do Estado, das Instituições e da Democracia (Diest) buscou apurar a configuração da justiça especializada no Brasil e propiciou métodos para subsidiar a atuação do CNJ na adoção de políticas orientadoras para admissão e funcionamento das varas da infância e juventude (CNJ, 2012 ii, p. 7).

Devido à complexidade e à especificidade dos temas que afetam a vida de adoles- 
centes, a justiça infantojuvenil se mostra como uma alternativa essencial para responder às demandas judiciais que permeiam a realidade dos jovens, situação que demanda um trâmite processual distinto do comum e exige preparo e estrutura diferenciada para lidar com questões sociais e afetivas intensas no meio familiar e comunitário (CNJ, 2012 ii, p. 9).

O estudo resultou no relatório de pesquisa Justiça Infantojuvenil - Situação atual e critérios de aprimoramento, que avalia os perfis sociodemográficos das comarcas brasileiras, analisa os perfis estrutural e forense das varas com competência em matérias de infância e juventude e averigua as regiões do país quanto à necessidade de investimentos do Judiciário nessa área.

Importa mencionar que, dentre as considerações elaboradas nesse relatório acerca das lacunas existentes na estrutura das varas da infância e juventude, na investigação do critério de juízes titulares em atuação na vara obteve-se o índice nacional de 69\% de juízes lotados nas varas exclusivas, o que significa que são 67 titulares atuando nas 91 unidades respondentes. Já em varas cumulativas - responsáveis por demandas não só da infância e juventude, mas também da família e do idoso -, esse índice apontou 82\% do total de titulares em atividade. A despeito de os números parecerem bons em um primeiro momento, há que se levar em consideração que a presença de um juiz titular exclusivo não é elemento suficiente para a devida prestação jurisdicional, mas, no caso em voga, muito mais importante é se indagar a respeito do perfil do magistrado - vocação, especialização e disponibilidade -, por ser esse um "requisito imprescindível ao enfrentamento de causas relativas à infância e juventude” (CNJ, 2012 ii, p. 51).

Destaque-se a constante atuação do $\mathrm{CNJ}$ ao emitir recomendações específicas aos Sistemas Estaduais de Atendimento Socioeducativo, no âmbito dos poderes executivos estaduais. É o que se observa em recente recomendação para o Estado de Minas Gerais. No mês de outubro de 2013, em Audiência Pública organizada pela Comissão de Direitos Humanos da Assembleia Legislativa de Minas Gerais, o juiz auxiliar da presidência do CNJ propôs uma parceria entre os três Poderes para a adoção de medidas para melhorias do sistema socioeducativo estadual. De acordo com o pronunciamento do magistrado, a superlotação das unidades de internação da capital Belo Horizonte é um dos maiores problemas enfrentados pelo sistema socioeducativo mineiro, haja vista a escassez desses estabelecimentos no interior do estado, sendo igualmente grave a deficiência técnica e numérica no quadro pessoal (AGÊNCIA CNJ DE NOTÍCIAS, 2013).

É fundamental refletir que o atual modelo de atendimento socioeducativo padece de velhas práticas e concepções que não só impedem que o novo surja e se consolide como ocultam a maximização do controle penal sobre os adolescentes. Muitas vezes, sob a imagem de um argumento protetivo, atende-se a um modelo maximizado de Direito Penal juvenil, desformalizado no que se refere à imposição das consequências jurídico-penais ao delito juvenil e altamente inflexível em sua execução (SPOSATO, 
2013, p. 103).

\section{A refração da própria Justiça}

No curso desta reflexão parece inquestionável a contribuição do Conselho Nacional de Justiça ao sistema de atendimento socioeducativo, especialmente depois que entrou em vigor a Lei n. 12.594/2012, na qual se redefinem desafios concretos para dar materialidade e obediência à lei em matéria de execução e financiamento dos programas socioeducativos e das medidas deles derivados.

Contudo, se no campo da política de atendimento a irradiação desses resultados é facilmente percebida, o mesmo não se pode dizer para a Justiça em seu âmbito próprio de decisão e funcionamento. A recente decisão proferida pelo Supremo Tribunal Federal (STF), em caráter liminar, legitimando a superlotação de uma unidade de internação em $15 \%$ de sua capacidade no Estado de São Paulo, coloca em xeque a capacidade de interferência positiva e transformadora dos mecanismos do CNJ para dentro de seu próprio espaço de operação. Vejamos.

Conforme art. $6^{\circ}$ do Provimento n. 1.436/07 do Conselho Superior da Magistratura do Estado de São Paulo, institui-se como competência do Poder Executivo, a transferência de adolescentes em cumprimento de medida de internação - no caso em estudo, papel desempenhado diretamente pela Fundação CASA -, respeitando-se o requisito da aproximação familiar e a necessidade de se informar tal transferência ao Juízo onde o adolescente se encontra internado provisoriamente ou em regime de semiliberdade, e para o qual ele foi transferido. O parágrafo único do art. $7^{\circ}$ desse mesmo Provimento prevê que em caráter excepcional, na hipótese de superado o número de vagas da unidade, caberá à Fundação CASA ou atender os adolescentes na unidade, sem ultrapassar o percentual de 15\% da capacidade estabelecida na portaria, ou removê-los para outras unidades próximas com mesma elegibilidade e área de abrangência ou, ainda, removê-los para as unidades da capital.

O Conselho Nacional de Justiça, por meio do Procedimento de Controle Administrativo n. 004636-19.2012.2.00.0000, considerou ilegal os dispositivos supracitados. Em resposta a esse entendimento, o Tribunal de Justiça de São Paulo impetrou Mandado de Segurança com pedido de liminar ao Supremo Tribunal Federal (STF), cuja decisão, proferida pelo ministro Dias Toffoli, relator da ação, foi lamentavelmente em sentido contrário à cognição do CNJ.

Dias Toffoli, em sua decisão, faz referência à petição inicial impetrada pelo Tribunal de Justiça de São Paulo, e diz que "ao determinar que incumbiria ao Juiz de Direito a escolha da unidade de internação em que será cumprida a medida socioeducativa de adolescente infrator, o CNJ não reconheceu a competência do Poder Executivo para tratar do assunto, pois a gestão de vagas nessas unidades é feita com a visão do todo, que 
não é do conhecimento de cada magistrado, individualmente". Para ele, compete ao Poder Executivo promover as transferências e as remoções dos adolescentes infratores, havendo contudo uma fiscalização dessa atuação por parte do Poder Judiciário. Acresce o ministro que o tema referente à transferência de adolescentes de uma unidade para outra envolve uma variada gama de áreas de conhecimento, com a intervenção de profissionais de diversas habilidades técnicas. Como compete ao Poder Executivo exercer a direção da Administração Pública, insere-se dentro dessa sua competência o gerenciamento de vagas nas unidades de cumprimento de medidas socioeducativas. Para ele, ademais, já há norma legal, editada pelo próprio CNJ (Resolução n. 165/12, artigo $6^{\circ}, \S 2^{\circ}$ ), determinando que o magistrado responsável pela fiscalização da unidade seja comunicado em 24 horas sobre eventual transferência e aprecie a legalidade da medida (BRASÍLIA, Supremo Tribunal Federal. Processo: Medida Cautelar em Mandado de Segurança 31902. Relator: Min Dias Toffoli., 2013).

O ministro justificou sua posição sobre o entendimento de que as transferências possibilitam ao jovem internado a proximidade com sua família - circunstância abrigada pelo princípio do melhor interesse do adolescente -, ainda que não se imponha nenhuma regra nesse sentido à Fundação CASA, reconhecendo assim como legal o art. $6^{\circ}$ do Provimento n. 1.436/07 do CSM-SP.

A decisão causa espécie na perspectiva de André Feitosa Alcântara, membro do Movimento Nacional de Direitos Humanos (MNDH), que pondera que essa decisão pode abrir portas para violações de direitos dos adolescentes que cumprem medida de internação (MARETTI, 2013), em seu agudo constraste com todo o trabalho que vem sendo realizado pelo Conselho Nacional de Justiça.

Para conferir legalidade ao parágrafo único do art. $7^{\circ}$ do referido Provimento, que autoriza a tolerância de até $15 \%$ de superlotação na capacidade das unidades de internação, Dias Toffoli argumentou que tal norma visa resguardar os melhores interesses dos adolescentes infratores, isto é, permanecerem internados em locais próximos às suas residências. $\mathrm{O}$ ministro procurou fundamentar sua decisão através de dados numéricos: em São Paulo há 8.400 adolescentes custodiados, sendo o número de vagas igual a 7.800 divididas em 116 unidades de internação. "São números que impressionam e falam por si, a demonstrar a magnitude do problema enfrentado para gerenciar tal agigantado sistema” (BRASÍLIA, Supremo Tribunal Federal. Processo: Medida Cautelar em Mandado de Segurança 31902. Relator: Min Dias Toffoli., 2013).

Se analisarmos a decisão tomando como referência algumas ponderações de François Ost, segundo as quais é no jogo da interpretação do direito que o juiz tem a oportunidade não só para se manifestar ou contradizer sua adesão ao sistema jurídico vigente, seus interesses e valores, mas também sua solidariedade e defesa da ordem social estabelecida (OST; KERCHOV, 2001 . p. 301), poderemos nos questionar sobre o que efetivamente dizem tais números: o princípio da excepcionalidade na aplicação da medida de internação está sendo respeitado? De quem é o melhor 
interesse atendido quando o Supremo Tribunal Federal legitima a superlotação de uma unidade de internação? Que tipo de atendimento socioeducativo pode ser realizado em um contexto de superlotação? Quais os efeitos da privação de liberdade nessas condições?

Aqui reside a paradoxal contradição. Se é verdade que o direito é uma mediação entre a política e a ética, deflagra-se a conveniência de que se articule o realismo das observações sociopolíticas, de um lado, às exigências normativas, de outro (OST; KERCHOV, 2001, p. 14).

De acordo com a ponderação do representante do MNDH, a concessão de liminar pelo Supremo pode incentivar os demais juízes a adotar a medida de internação como solução, deixando de utilizá-la como medida excepcional que deve ser, conforme determinação expressa no art. 121 do Estatuto da Criança e do Adolescente (ECA) e no art. 35 do SINASE. "A decisão reafirma a posição de alguns juízes que entendem que a internação deve ser adotada corriqueiramente.” E, por permitir que se exceda o limite de vagas em 15\%, pode também fazer com que o Executivo se acomode com a quantidade de vagas e as unidades que possui, deixando de empreender esforços para o aprimoramento das unidades (MARETTI, 2013) - e consequentemente, o aprimoramento de todo o sistema.

Ora, não há como se pensar que o princípio da excepcionalidade da imposição de medidas de privação de liberdade esteja sendo respeitado quando, de acordo com dados fornecidos pelo próprio Conselho Nacional de Justiça, ao se analisar a sobrecarga das unidades de internação nacionais constata-se que no Brasil não restam vagas, haja vista a taxa de ocupação das unidades chegar a 102\% (CNJ, 2012 i, p. 39).

Dias Toffoli, em sua decisão, discorre que o Estado de São Paulo, por ser o mais desenvolvido e o mais populoso da Federação, enfrenta "problemas hercúleos nesse campo, que requerem medidas drásticas para que sejam devidamente equacionados, sempre procurando resguardar o decantado melhor interesse dos adolescentes". Remete aqui o ministro ao direito que tem o adolescente de ser internado em unidade próxima à residência de sua família (BRASÍLIA, Supremo Tribunal Federal, Processo: Medida Cautelar em Mandado de Segurança 31902. Relator: Min Dias Toffoli. 2013).

Todavia, uma linha de raciocínio que autoriza a superlotação em 15\% vai de encontro às recomendações legais do ECA e SINASE e às recomendações institucionais do Programa Justiça ao Jovem. Sustentar um posicionamento diametralmente oposto ao que prega o Estatuto, a lei do SINASE e os estudos produzidos pelo Conselho Nacional de Justiça, embasando-se no princípio do melhor interesse do adolescente, parece eufemisticamente ilógico.

José Rodrigo Rodriguez e Carolina Cutrupi Ferreira chamam atenção para a necessidade de se refletir sobre a qualidade da fundamentação das sentenças. Em um contexto democrático, "fundamentações deficientes (...) marcadas por uma argumentação incoerente, mesmo que construída a partir de material jurídico (...) podem contri- 
buir para o enfraquecimento do Estado de Direito (...)" (FERREIRA; RODRIGUEZ, 2013, p. 257).

O melhor interesse do adolescente não pode ser utilizado como justificativa para a superlotação de unidades de internação, pois em sentido inverso visa que os atores do sistema judicial não operem unicamente sob a lógica do castigo. O princípio do melhor interesse reforça o entendimento de que o sistema de justiça juvenil deve ser exercido a partir de uma interpretação sistemática e abrangente do ECA, como forma de garantir que o direito penal juvenil seja subsidiário às demais disposições de lei e, sobretudo, reduza-se à menor intervenção possível na vida e desenvolvimento do adolescente. De maneira semelhante, o princípio também interfere na execução das medidas. O melhor interesse do adolescente implica não só o estrito respeito ao princípio da proporcionalidade quando da imposição da medida socioeducativa, como também (e de forma igualmente importante) a percepção das condições objetivas do cumprimento da medida escolhida para o adolescente (SPOSATO, 2006, p. 110 e 111).

Isso posto, legalizar a superlotação em 15\% da capacidade institucional de custódia de adolescentes parece atender exclusivamente a interesses de ordem pragmática e punitivo-simbólica que não dizem respeito à decisão: "infelizmente, a prática de atos infracionais (alguns marcados por rara crueldade e acentuada violência) aumenta gradativamente, a impor ao Poder Judiciário a tomada de medidas enérgicas" (BRASÍLIA, Supremo Tribunal Federal. Processo: Medida Cautelar em Mandado de Segurança 31902. Relator: Min Dias Toffoli., 2013).

Ademais, não parece justificável que a Corte Suprema decida adiando o pleno cumprimento da legislação vigente aplicável à matéria. Cabe relembrar as palavras de Dworkin quando diz que quando o governo não leva os direitos a sério, evidentemente não leva a lei a sério. (DWORKIN, 2011, p. 314).

Outro exemplo eloquente da difícil articulação entre o que recomenda o Conselho Nacional de Justiça e as práticas efetivadas nos Tribunais, também no nível estadual de jurisdição, se refere ao caso ocorrido em 2007 no Estado do Pará, que teve desdobramentos recentes.

Entre os meses de outubro e novembro de 2007, a mandado da juíza Clarice Maria de Andrade Rocha, a adolescente L. A. B. A., de 15 (quinze) anos de idade, que cometeu ato infracional equiparado a tentativa de furto, foi presa por 26 (vinte e seis) dias em uma cela, dentro da Delegacia de Polícia da cidade de Abaetetuba (PA), na presença de 20 (vinte) homens. Durante os dias em que lá passou, a adolescente sofreu tortura e abuso sexual.

O caso foi denunciado pelo Conselho Tutelar do Município de Abaetetuba, e o CNJ abriu processo administrativo contra a magistrada. No julgamento administrativo, que ocorreu no ano de 2010, o Conselho entendeu, por unanimidade, que a juíza tinha conhecimento da situação da vítima e que havia adulterado data de ofício para a 
Corregedoria Geral do Estado, em que pedia a transferência da menor de idade quando já era tarde demais. O CNJ determinou a aposentadoria compulsória à magistrada.

A Associação de Magistrados do Pará (Amepa) entrou então com recurso no Supremo Tribunal Federal contra a decisão proferida pelo CNJ, julgado em 2011 oportunidade em que a Suprema Corte entendeu que a punição estipulada pelo Conselho fora exagerada, anulando portanto a aposentadoria da juíza Clarice Maria de Andrade Rocha. No último dia 2 de outubro de 2013, o Tribunal de Justiça do Pará promoveu a juíza por meio do critério de "merecimento".

\section{CONSIDERAÇÕES FINAIS}

O percurso reflexivo ora proposto buscou destacar o papel pioneiro e inovador do Conselho Nacional de Justiça (CNJ) no trato do sistema socioeducativo brasileiro, colocando em relevo o papel de fiscalização, monitoramento e de gestão de informações que o sistema de justiça possui nesse cenário.

O processo de normatização do SINASE e a recente aprovação da Lei n. 12.594/2012 são evidências de um momento sociopolítico de extrema relevância para a reorganização dos serviços e políticas públicas voltadas aos e às adolescentes em conflito com a lei no país, o que vem exigindo a reorientação de práticas institucionais até então cristalizadas em uma lógica ainda tutelar e em alguns casos altamente punitivo-repressiva. Para tanto, são necessários instrumentos e mecanismos mais eficazes de diagnóstico, monitoramento e avaliação.

A natureza e a abrangência da intervenção judicial em sua intersecção com o sistema de atendimento socioeducativo favorece o acúmulo e a sistematização de informação privilegiada, fundamental para o aperfeiçoamento do atendimento socioeducativo e da própria Justiça.

Contudo, um largo caminho ainda carece ser percorrido. Desafiadoramente parecem residir, no campo próprio de operação e funcionamento do Conselho, os maiores entraves que se traduzem pela necessária transformação e superação de lógicas decisionistas que priorizam razões de Estado em detrimento dos direitos e garantias individuais, como se revela nitidamente nas decisões proferidas pelo Supremo Tribunal Federal (STF), legitimando a superlotação de uma unidade de internação em 15\% de sua capacidade e anulando a aposentadoria de uma magistrada responsável pelo encarceramento de uma adolescente em uma cela com 20 (vinte) homens, durante quase 1 (um) mês.

Considerando o advento da Lei n. 12.594/2012, mais conhecida como Lei do SINASE, como novo marco regulatório para todo o sistema de atendimento socioeducativo, e tendo em vista a crescente ampliação da governança judicial atrelada à compreensão da prestação jurisdicional como serviço público, lançado está um novo desafio para o Conselho Nacional de Justiça: não só contribuir para melhor atuação 
e funcionamento do próprio sistema de justiça, na adoção de caminhos orientadores para a admissão e funcionamento das varas da infância e juventude como também operar um verdadeiro reordenamento institucional, com profunda alteração da cultura política e efetiva irradiação sobre os operadores de direito.

: ARTIGO APROVADO (02/12/2013) : RECEBIDO EM 31/07/2013

\section{NOTAS}

1 O Sistema Nacional de Atendimento Socioeducativo - SINASE é a política pública referente à implementação das medidas socioeducativas previstas no Estatuto da Criança e do Adolescente - ECA, como resposta ao envolvimento de adolescentes com a prática de atos infracionais. A construção do SINASE tem como protagonistas o Conselho Nacional dos Direitos da Criança e do Adolescente - CONANDA em conjunto com a Secretaria Nacional de Promoção e Defesa dos Direitos da Criança e do Adolescente (SNPDCA) com o objetivo de normatizar e harmonizar as práticas de gestão e execução em torno do atendimento socioeducativo.

2 Art. 21. Cabe ao Poder Judiciário, sem prejuízo das competências do Ministério Público, fiscalizar a execução dos programas socioeducativos em meio aberto e aqueles correspondentes às medidas privativas de liberdade, zelar pelo efetivo respeito às normas e princípios aplicáveis à modalidade de atendimento prestado e pela qualidade e eficácia das atividades desenvolvidas, observado o disposto nos arts. 90, $\S 3^{\circ}$, incisos I e II, e 95 do Estatuto da Criança e do Adolescente e o disposto na Lei n. 12.594, de 18 de janeiro de 2012 (Resolução n. 165. CONSELHO NACIONAL DE JUSTIÇA. 2012).

\section{REFERÊNCIAS BIBLIOGRÁFICAS}

AGÊNCIA CNJ DE NOTÍCIAS. CNJ recomenda união de esforços para melhorar o sistema socioeducativo de Minas Gerais. Disponível em: < http://www.cnj.jus.br/noticias/cnj/26509-cnj-recomenda-uniao-de-esforcos-para-melhoraro-sistema-socioeducativo-de-minas-gerais $>$. Acesso em: 9 out. 2013.

AKUTSU, L; GUIMARÃES, T. Dimensões da Governança Judicial e sua Aplicação ao Sistema Judicial Brasileiro. Revista Direito GV, São Paulo, v. 8, n. 1, pág. 183-202, 2012.

BOTTINI, Pierpaolo. Modernização do Poder Judiciário. Porto Alegre: TRF - $4^{a}$ Região, 2009. (Cadernos de Administração da Justiça - Planejamento Estratégico 2009: módulo 6).

BRASIL. Lei n. 8.069, de 13 de julho de 1990. Lei n. 12.106, de 02 de dezembro de 2009.

Lei n. 12.594, de 18 de janeiro de 2012.

Supremo Tribunal Federal. Medida Cautelar em Mandado de Segurança 31902. Impetrante: Tribunal de Justiça

do Estado de São Paulo. Impetrado: Presidente do Conselho Nacional de Justiça. Relator: Min,. Dias Toffoli. Brasília, 26 de fevereiro de 2013.

BRASIL - CNJ. Resolução n. 165, de 16 de novembro de 2012.

BRASIL - Conanda. Resolução n. 113, de 19 de abril de 2006.

CAMPILONGO, Celso Fernandes. Direito e Diferenciação social. São Paulo: Saraiva, 2011. 
CEDCA/PE - Conselho Estadual de Defesa dos Direitos da Criança e do Adolescente de Pernambuco. Plano de Reordenamento de Sistema Socioeducativo do Estado de Pernambuco, 2010.

CNJ. Justiça Infantojuvenil - Situação atual e critérios de aprimoramento. Conselho Nacional de Justiça. Instituto de Pesquisa Econômica Aplicada. 2012.

Panorama Nacional - A Execução das Medidas Socioeducativas de Internação. Conselho Nacional de Justiça. 2012.

DWORKIN, Ronald. Levando os Direitos a Sério. Tradução de Nelson Boeira. São Paulo: WMF Martins Fontes, 2011. FERREIRA, Carolina Cutrupi; RODRIGUEZ, José Rodrigo. Como decidem os juízes? Sobre a qualidade da jurisprudência brasileira. In: RODRIGUEZ, José Rodrigo (coord.); SILVA, Felipe Gonçalves (Coord.). Manual de Sociologia Jurídica. São Paulo: Saraiva, 2013.

FILHO, I. N. R. Accountability e Independência Judiciais: Uma Análise da Competência do Conselho Nacional de Justiça (CNJ). Revista de Sociologia e Política, Curitiba, v. 21, n. 45, pág. 29-46, 2013.

LAVIGNE, Rosane M. Reis. Política judiciária no Conselho Nacional de Justiça: e a perspectiva de gênero?. Dissertação (mestrado). Escola de Direito do Rio de Janeiro da Fundação Getúlio Vargas. Rio de Janeiro, 2010.

MARETTI, Eduardo. Decisão de Toffoli aceita violação de direitos de menores infratores. Disponível em:

<http: / /www.mndh.org.br/index.php?option=com_content\&task=view\&id=3262>. Acesso em: 25 jul. 2013.

ORGANIZAÇÃO DAS NAÇÕES UNIDAS. Manual para a Mensuração de Indicadores de Justiça Juvenil. Nova York, 2006. OST, François; KERCHOV, Michel van de. Elementos para una Teoria Critica Del Derecho Coleccion Teoria y Justicia. Universidad Nacional de Colombia. Bogotá: Editorial Unibiblos, 2001.

REDAÇÃO (Revista Forum). CNJ proíbe que Fundação Casa exceda limite de internações. Revista Forum, 5 de novembro de 2012. Disponível em: < http://revistaforum.com.br/spressosp/2012/11/cnj-proibe-que-fundacao-casa-exceda-limite-de-internacoes/>. Acesso em: 25 jul. 2013.

RIBEIRO, L. A Emenda Constitucional 45 e a Questão do Acesso à Justiça. Revista Direito GV, São Paulo, v. 4, n. 2, pág. 465-492, 2008.

SPOSATO, Karyna Batista. Direito Penal de Adolescentes - elementos para uma teoria garantista. São Paulo: Saraiva, 2013. . O Direito Penal Juvenil. São Paulo: Revista dos Tribunais, 2006.

Karyna Batista Sposato

Universidade Tiradentes

Programa de Pós-Graduação em Direito (PPGD)

Avenida Murilo Dantas, n. 300

Campus Farolândia, Bloco F - 49032-490

Aracaju - Sergipe - Brasil

karyna.sposatolapq.cnpq.br
Coordenadora do Programa de Pós-graduação EM DIREITO DA UNIVERSIDADE TIRADENTES (UNIT) /

Mestrado em Direitos Humanos

DOUTORA EM DIREITO

\section{Marisa Meneses de Andrade}

Universidade Tiradentes

Programa de Pós-Graduação em Direito (PPGD)

Avenida Murilo Dantas, n. 300

Campus Farolândia, Bloco F - 49032-490

Aracaju - Sergipe - Brasil

mah.deandradelahotmail.com
GRADUANDA EM DIREITO PELA UNIVERSIDADE TIRADENTES (UNIT) 
